\title{
Real effects of Quantitative Easing at the Zero-Lower Bound: Structural VAR-based evidence from Japan
}

\author{
Heike Schenkelberg* \\ MGSE \\ University of Munich
}

\author{
Sebastian Watzka ${ }^{\dagger \ddagger}$
}

Seminar for Macroeconomics

University of Munich

3 February 2011

\begin{abstract}
Using monthly post-1995 Japanese data we propose a new sign-restriction based approach to identify monetary policy shocks when the economy is at the zero-lower bound. The identifying restrictions are thoroughly grounded in liquidity trap theory. Our results show that a quantitative easing shock can lead to a significant but temporary rise in industrial production. The effect on inflation, however, is not significantly different from zero. Our results are robust to different specifications, in particular to the further identification of aggregate demand and supply shocks under liquidity trap conditions. Accordingly, our results imply that while the Japanese Quantitative Easing experiment was successful in stimulating economic activity in the shortrun, it did not lead to any increase in the inflation rate. We believe these results are interesting not only for the Japanese economy, but also for other advanced economies, such as the U.S., where monetary policy is constrained by the ZLB.
\end{abstract}

JEL Classification: E43, E51, E52, E58

\footnotetext{
*Email: heike.schenkelberg@lrz.uni-muenchen.de

†Email: sebastian.watzka@1rz.uni-muenchen.de. Address: Ludwigstr. 28/RG, 80539 Munich, Germany. Telephone +49 892180 2128.(Corresponding author)

$\ddagger$ We would like to thank Gerhard Illing, Helmut Lütkepohl, Gernot Müller, Ekkehart Schlicht, as well as seminar participants at the University of Munich for helpful comments. All errors are our own.
} 


\section{Introduction}

We study the real effects of Quantitative Easing (QE) in a structural VAR (SVAR) when the shortterm interest rate is constrained by the Zero-Lower-Bound (ZLB). Using monthly Japanese data since 1995 - a period during which the Bank of Japan's target rate, the overnight call rate, has been very close to zero - and sign restrictions based on liquidity trap theory, we find that an increase in reserves leads to a significant 0.7 percent rise in industrial production on impact. This rise lasts for about two years. On the other hand, our results indicate that the same shock has no effect on inflation. Thus our results provide mixed evidence on the successfulness of QE in Japan. Whilst real economic activity does seem to pick up after a QE-shock, this does not seem to affect inflation in such a way that Japan could exit its deflationary period through such a policy shock.

However, this conclusion strictly holds only under the usual caveat in SVAR- analysis that the monetary policy shock we consider must be a small one - one that is not allowed to change the policy regime or any other of the structural relations we estimate. Whilst we argue this is precisely the kind of shock that central banks currently inflict on our economies, we should be careful not to conclude that any more aggressive policy changes by central banks to escape the deflationary period of the liquidity trap ${ }^{1}$ are doomed to fail.

Our study adds to the existing literature in various important ways. First, focusing specifically on post-1995 Japanese data where the policy rate of the Bank of Japan, the call rate, was virtually zero, ${ }^{2}$ allows us to identify a monetary policy shock under liquidity trap conditions. We call such a shock unconventional monetary policy shock or QE-shock for short. Second, including standard macro variables in our VAR allows us to study the effects of such a QE-shock on a broader set of variables than usually studied in the literature on unconventional monetary policy effects. In particular, our approach allows us to study the effects of a QE-shock on real economic activity and on the inflation rate - the two variables of ultimate interest to the central bank. Third, using a sign-restriction approach to identify our QE-shock allows us to remain agnostic about whether, how, and when real activity and inflation respond to the QE-shock. Fourth, because our restrictions are firmly grounded in liquidity trap theory we believe they are credible in the sense of Sims (1980) and that what we measure in our SVAR is indeed the structural QE-shock we are aiming at. Finally, because shortterm policy rates in the US, the Euro Area, the UK and other economies around the world are currently very close to zero and therefore possibly

\footnotetext{
${ }^{1}$ For instance along the lines of Krugman (1998) or Svensson (2003).

${ }^{2}$ See Figure 1.
} 
also constrained by the ZLB, our results shed light on the effects of the currently implemented nonstandard policy measures adopted by the leading central banks in the world.

The rest of the paper is organised as follows: The next section summarises the key findings in the literature on monetary policy effects at the Zero-Lower-Bound (ZLB). Section 3 then briefly discusses key features of the main monetary policy decisions implemented by the Bank of Japan since the stock and housing market crashes in the early 90s. Our key identification strategy using sign-restrictions based on liquidity trap theory is explained in Section 4. Data and results are then presented in Sections 5 and 6 respectively. Section 7 finally concludes.

\section{Effects of monetary policy shocks under liquidity trap conditions}

The effects of monetary policy shocks when monetary policy is not constrained by the ZeroLower-Bound (ZLB) has been well documented in the literature. Of course, arguments are still ongoing as to how the monetary shock under normal times is best identified. But by and large there is a broad consensus that expansionary monetary policy, say by lowering the policy interest rate, affects inflation and output positively, but only very sluggishly and only temporarily. ${ }^{3}$ This of course is roughly in line with our macroeconomic theories on how monetary shocks, be they through changes in the interest rate or the monetary base, affect the real economy under normal times when the interest rate is not constrained by the ZLB.

It is somewhat surprising therefore that there is much less empirical evidence on the real effects of monetary policy shocks when monetary policy is in fact constrained by the ZLB. Notable exceptions are Baumeister and Benati (2010), Kamada and Sugo (2006) and Lenza et al. (2010). ${ }^{4}$ One obvious reason might be that most economies until very recently have not been in such a situation and that sample periods to use in estimation would thus be notoriously short. However, it is also true that at least since 2000, when the Fed was fast to lower the Federal Funds rate to very low levels in response to the bursting of the IT-bubble, there has been an important theoretical discussion amongst central bankers as how to avoid liquidity traps and how to escape them once an economy found itself in the trap. ${ }^{5}$ Unfortunately, with some exceptions, the

\footnotetext{
${ }^{3}$ Compare Christiano et al. (1998). But note different identifying restrictions do in fact lead to slightly different results, compare Uhlig (2005) and Lanne and Lütkepohl (2008).

${ }^{4}$ We comment below on how our study differs from these.

${ }^{5}$ See e.g. Bernanke (2002), Bernanke and Reinhart (2004), Krugman (1998) or Svensson (2003).
} 
corresponding empirical evidence evaluating those theories has however not been forthcoming. The recent financial crisis has led to renewed interest in the empirical effects of the so-called unconventional monetary policies implemented by the leading central banks. However, most of these studies focus on the effect unconventional policies have on various interest rates or interest rate spreads. They do not study the effects of those policies on other standard macro variables like output or inflation. But these variables of course are the key variables of interest to the central bank and the public and of course important for welfare considerations. Thus there is by now a growing body of literature that studies the effects of unconventional monetary policy on such financial market variables like interest rates, spreads or the entire yield curve. Recent examples include Bernanke et al. (2004), Gagnon et al. (2010), Hamilton and Wu (2010) and Stroebel and Taylor (2009) for the US, Meier (2009) for the UK, ECB (2010) for the Euro Area, and Oda and Ueda (2007) and Ueda (2010) for Japan. Broadly speaking, these studies do find negative effects on yield spreads of unconventional policies, or more precisely of announcements of such policies, in the sense that the yields of various assets do tend to decline thereby narrowing the spread to the corresponding riskless rate. However, these effects are generally found to be rather small. For instance, Hamilton and Wu (2010) find that a purchase of 400 billion US dollars in 10-year US Treasury Bonds would lead to a 14 basis points fall in the 10-year yield. Gagnon et al. (2010) find that the same policy measure would lower longterm yields by 20 basis points. Meier (2009) estimates that the Bank of England's QE-related asset purchases lowered gilt yields by around 40-100 basis points.

The recently announced additional round of monetary easing by the Fed on 3 November 2010 further stimulated this debate about the effectiveness of the unconventional monetary policy measures. The FOMC announced that it "intends to purchase a further 600 billion dollars of longer-term Treasury securities by the end of the second quarter of 2011, a pace of about 75 billion dollar per month." 6

It is important to note that the theoretical impact of such a policy announcement on longterm yields is far from clear. Most theoretical studies (see e.g. Doh (2010)) refer to some kind of imperfect substitutability between assets and explain the expansionary effect of such a policy decision by arguing that the purchase of longterm bonds by the central bank will naturally lower longterm bond yields, because the central bank buys those bonds at a higher price than the market charges. This lower longterm yield on government bonds then feeds through - via portfolio shifts (Meltzer, 1995) - to other asset markets, like the corporate bond market and the stock

\footnotetext{
${ }^{6}$ See FOMC statement from 3 November 2010, http://www.federalreserve.gov/newsevents/press/monetary/20101103a.htm
} 
market. Longterm financing for investment and durable goods becomes cheaper thereby stimulating aggregate demand. In other words, the central bank cuts through the traditional interest rate channel by directly lowering longterm yields. Being constrained by the ZLB the traditional interest channel which normally lowers longterm yields through the expectations hypothesis does not function anymore and the central bank circumvents this by directly intervening in the market for longterm bonds. This theoretical argument is partly supported by the empirical evidence of the above mentioned studies.

However, from a theoretical point it is not clear that longterm yields are indeed supposed to fall after such a policy announcement. Indeed, if market participants believe the Fed intervention is successful in stimulating the economy by increasing aggregate demand, inflation and real rates are likely to rise in the future. Thus inflationary expectations as of today should rise and longterm nominal yields should in fact rise. In other words, the effectiveness of such a policy move might instead be seen by rising longterm yields, not by falling yields. In fact, falling longterm rates would then be a sign that the Fed policy was not successful. ${ }^{7}$ And indeed, since Fed officials first announced the possibility of further monetary easing in October 2010 yields on nominal 10 -year US Treasury bonds have risen by almost 100 basis points. Because real yields from TIPS have also risen by about 60 basis points, longterm inflation expectations in the US have risen by around 40 basis points since the first QE2-mentionings by Fed officials.

This remark allows us to finally discuss the ways in which our study differs from the above mentioned three studies. First, our study differs from Baumeister and Benati (2010) mainly by using a different set of variables and corresponding sign restrictions. Because of the above remarks we prefer not to restrict any spreads or identify an expansionary monetary policy shock by a reduction in spreads. Instead we try to be as agnostic as possible and only restrict the responses of the call rate, the current account holdings (or reserves) of banks at the Bank of Japan, and the stock price. Second, our study differs from Kamada and Sugo (2006) by not having to rely on an intermediate monetary indicator which captures the monetary stance in their model. In our model monetary stance is fully determined by the level of current account holdings and an unchanged call rate. We believe this is more reliable because these variables are more directly under the control of the central bank than any intermediate variables. Third, our study differs from Lenza et al. (2010) most obviously by considering a different country for which we have longer time series. We further differ from their study by carrying out traditional SVAR-impulse response analysis. Lenza et al. (2010) instead estimate their model and carry-

\footnotetext{
${ }^{7}$ On this see e.g. Illing and Watzka (2010), Siegel (WSJ, 14 Dec 2010) or Wolf (FT, 14 Dec 2010).
} 
out counterfactual policy analysis under the assumption that the remaining model remained unchanged. Our traditional method allows us to carry out policy analysis without such a strong assumption.

\section{Monetary Policy in Japan since the late 1980s}

This section briefly summarises key monetary policy developments in Japan since the late 1980s/early 1990s - in other words since the bursting of the Japanese stock and real estate bubbles. We only sketch key developments, for a thorough discussion please consult Mikitani and Posen (2000), Ugai (2007) and Ueda (2010). We divide this period into pre- and post-1995 based on the behaviour of the Bank of Japan's target interest rate, the call rate, which has been lowered by the Bank of Japan to virtually zero during 1995. Figure 1 shows key macroeconomic variables for Japan since 1981.

Figure 1: Key macroeconomic variables in Japan since 1981. The thick line indicates 1995.

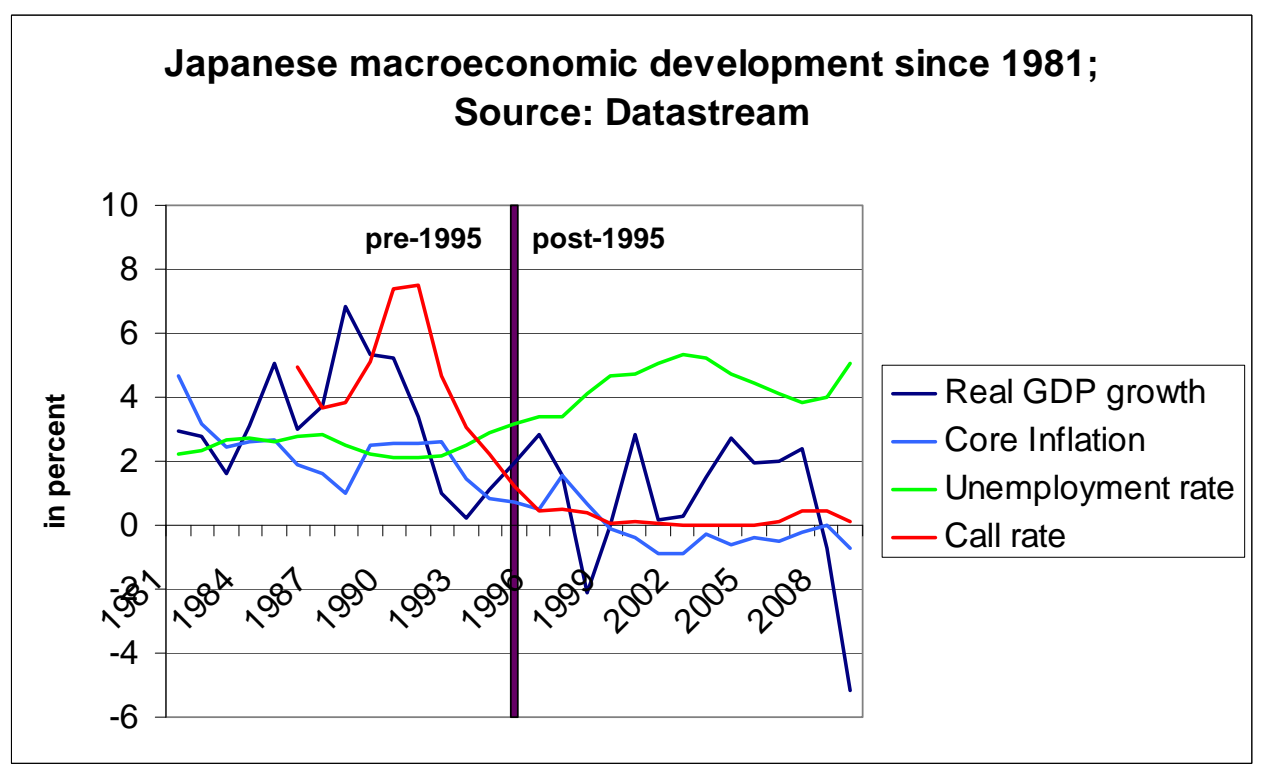

The figure reveals the widely documented behaviour of the dramatic fall in real GDP growth rates after the bursting of the asset prices bubbles in 1990/91. Whilst GDP grew in the pre-1991 period by an average rate of 3.9 percent per year, it slowed down to only 0.8 percent post-1991. This of course is the numerical basis for the well-known label "Japan's lost decade." Meanwhile 
the notoriously low Japanese unemployment rate has more than doubled while the core inflation rate has steadily trended below zero since 2000 . The following subsections give some more details to Japanese monetary policy pre- and post-1995.

\subsection{The bursting of the bubbles and delayed monetary policy reaction}

The bursting of the stock market bubble can be seen in Figure 2. The stock market was rising dramatically until around 1990. The figure shows that this went together with rapid increase in industrial production under fairly low and constant rates of inflation (compare also Figure 1).

Figure 2: Industrial production, Consumer Price Index and Tokyo stock index since 1980. The stock market bubble burst in 1990. Source: Datastream

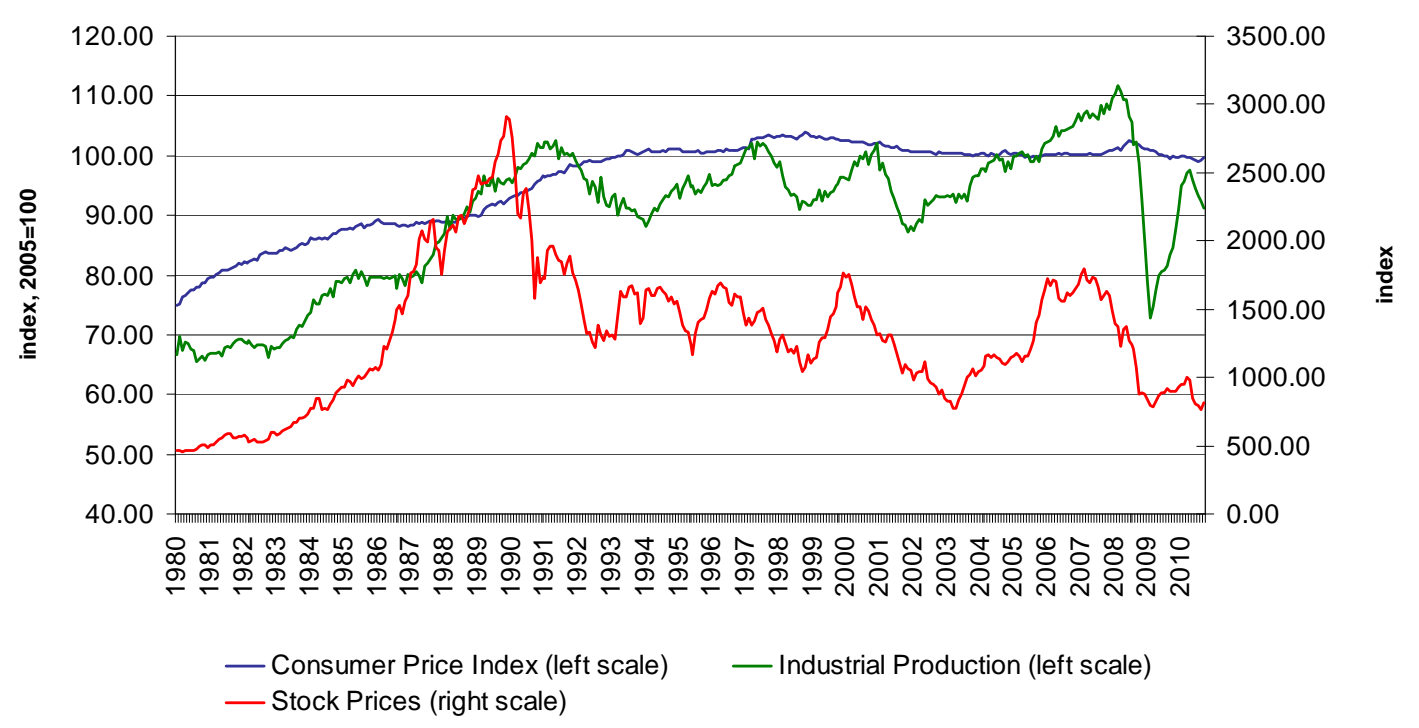

Realising that the elevated stock and land prices seemed out of touch with fundamentals the Bank of Japan did in fact continuously increase the call rate (compare again Figure 1). Optimism turned into pessimism around 1990/91 and both stock and land prices started falling rapidly. It is nowadays widely agreed (see e.g. Jinushi et al. (2000)) that the initial response of the Bank of Japan to the bursting of the asset price bubbles was too slow and not aggressive enough. In fact, Figure 1 shows that the call rate was high until 1992/3 and then only lowered very gradually until it reached 0.5 percent in the last quarter of 1995 . 


\section{$3.2 \quad$ Post-1995}

But even with its key policy rate at 0.5 percent and therewith close to zero, the Bank of Japan was very slow in implementing unconventional expansionary policy measures. In fact, only in 1999 did the Bank of Japan officially introduce its so-called zero interest rate policy (ZIRP) when it lowered the call rate to 0.03 percent (see Figure 3 ). It also tried to steer market expectations by adding commitments to its policy statements indicating that it would keep the call rate low for longer time.

Figure 3: Key Bank of Japan interest rates since 1980. The call rate has been the Bank of Japan's main policy rate between the mid-80s and early 2000. Source: Datastream

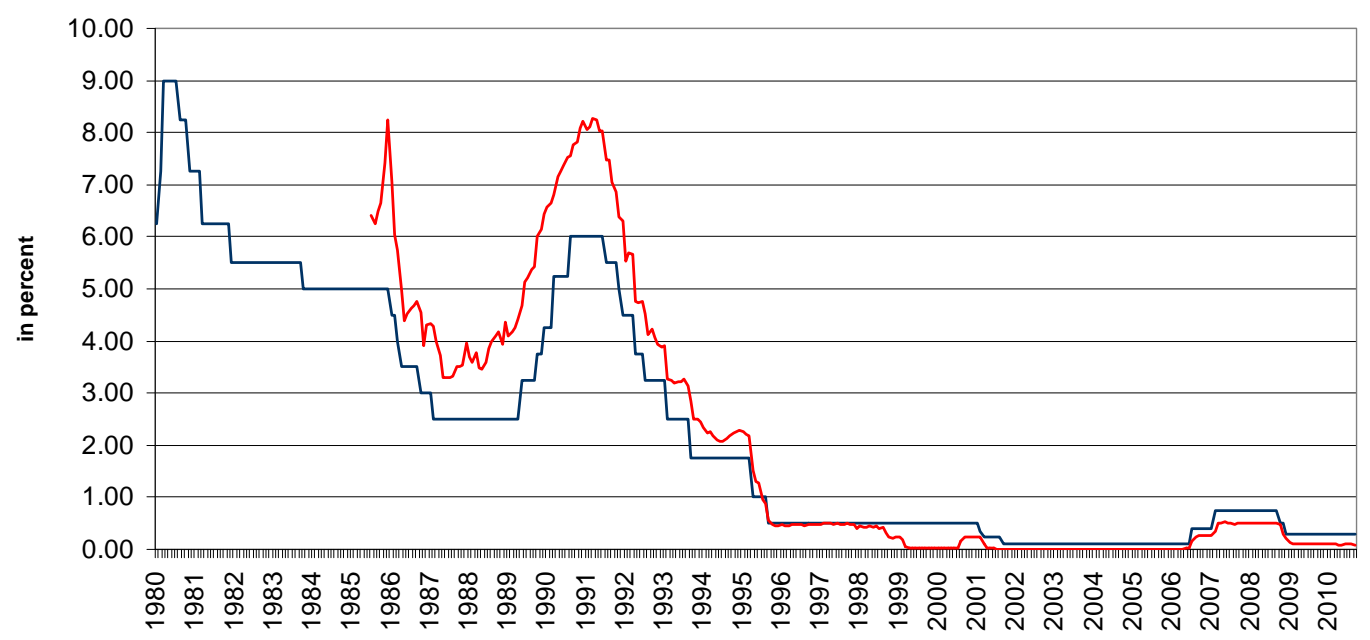

— Basic Loan and Discount Rate _ Call Rate (uncollateralized overnight)

When the Japanese economy started to recover slightly in 2000 with real GDP growth of 2.8 percent, the call rate was raised to 0.25 percent and ZIRP was officially ended.

However, the worldwide economic recession following the bursting of stock market bubbles in response to the IT-bubble led to renewed macroeconomic problems in Japan. This time the Bank of Japan introduced a more aggressive policy programme. From March 2001 until March 2006 it implemented the so-called "Quantitative Easing Policy" (QEP) which consisted basically of three elements: (i) the operating target was changed from the call rate to the outstanding current account balances held by banks at the Bank of Japan, (ii) to commit itself to continue providing ample liquidity to banks until inflation stabilised at zero percent or a slight increase, 
and (iii) to increase the amount of outright purchases of longterm Japanese government bonds. ${ }^{8}$

Figure 4: Monetary aggregates in Japan. Quantitative Easing was implemented between 2002 and 2006. Source: Datastream

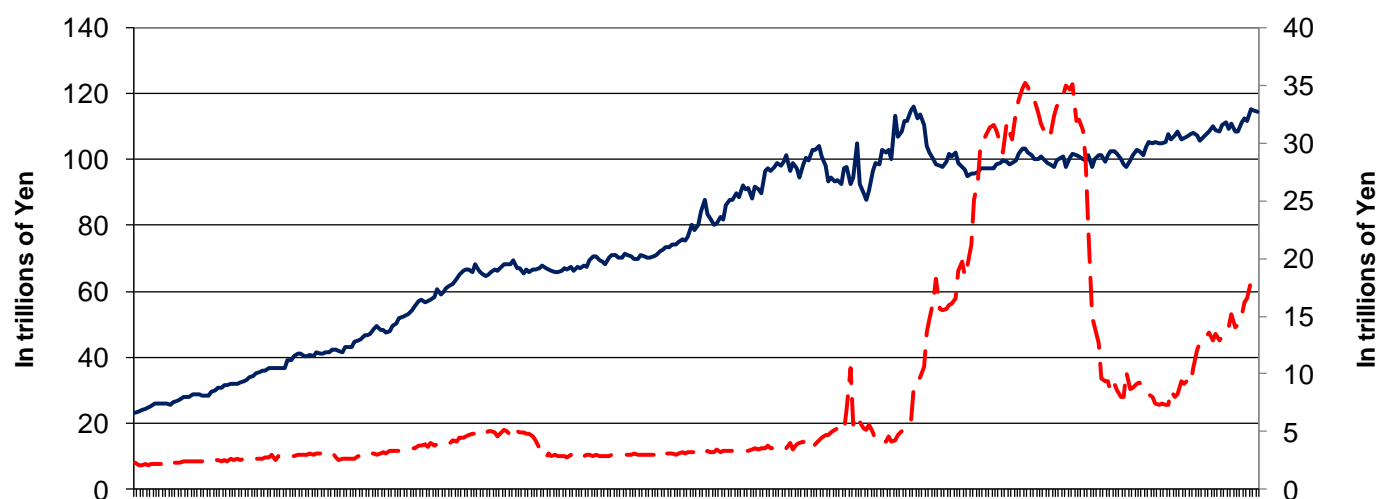

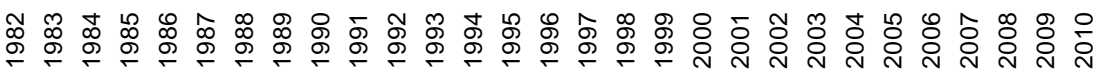

$-\mathrm{M} 2+\mathrm{CDs}$ (left scale) $\quad-\cdot \mathrm{M} 0$ - Current Account Balances (right scale)

The monetary development and the effect of the Bank of Japan's QEP measures can be seen in Figure 4. We plot that part of the monetary base that is the current account holdings of banks at the Bank of Japan, in other words these are bank reserves held at the central bank. The figure clearly shows the enormous increase in reserves during the QEP period and later again when the recent financial crisis hit. At the same time we see that the growth rate of M2 and Certificates of Deposits (CDs) steadily slowed since 1980.

Having these macroeconomic and monetary developments in mind we next want to present our identification strategy based on the reasonable assumption that the Bank of Japan since 1995 did not conduct its monetary policy through the call rate anymore - which was constrained by the ZLB - but by changing the reserve holdings of banks at the Bank of Japan.

\footnotetext{
${ }^{8}$ See the authorative survey by Ugai (2007) for more details.
} 


\section{Identification of structural shocks based on liquidity trap theory}

\subsection{Benchmark identification scheme}

To analyse the effects of monetary policy on economic activity and inflation at the ZLB, the following reduced-form VAR model is estimated:

$$
Y_{t}=c+A(L) Y_{t-1}+u_{t}
$$

where $Y_{t}$ is a vector of endogenous variables, $c$ is a vector of intercepts and linear trends, $A(L)$ is a matrix of autoregressive coefficients of the lagged values of $Y_{t}$ and $u_{t}$ is a vector of error terms. In our benchmark regression we include the following eight variables in the system:

$$
Y_{t}=\left[P_{t}, P_{t}^{S}, I P_{t}, R E S_{t}, E X_{t}, R_{t}, L T Y_{t}\right]
$$

where $P_{t}$ denotes the consumer price index, $P_{t}^{S}$ stands for the Nikkei stock price index and $I P_{t}$ indicates the Japanese industrial production. Moreover, we include reserves $\left(R E S_{t}\right)^{9}$ and the real effective exchange rate of the Yen against other currencies $\left(E X_{t}\right)$ as well as the call rate $\left(R_{t}\right)$. Finally, the 10-year yield of Japanese government bonds is included in the set of regressors. Except for the call rate and the longterm yield, all variables are seasonally adjusted and included as log-levels ${ }^{10}$. We do not include the variable measuring the money supply (M2 + CDs) since a number of empirical studies conclude that the relationship between money supply and economic activity or prices disappeared in the course of the $1990 \mathrm{~s}^{11}$. This is line with the development of this variable given in Figure 4 showing that during the period of massive quantitative easing in the early 2000's M2 did in fact not increase with the monetary base. These observations imply that the money stock is not likely to be an important variable with respect to the transmission of monetary policy during the 1990's and 2000's. A detailed description of the data is given in Section 5 .

\footnotetext{
${ }^{9}$ As a measure of reserves we consider outstanding current account balances held at the Bank of Japan, which is a base money component.

${ }^{10}$ According to Sims et al. (1990) this leads to consistent parameter estimates even in the presence of unit roots.

${ }^{11}$ See e.g. Miyao (2005)
} 
The VAR model is estimated by means of Bayesian methods using monthly data over the period January 1995 to September 2010. In the benchmark case, six lags of the endogenous variables are included in the estimation. As in Uhlig (2005), we identify the monetary shock by imposing sign restrictions on the impulse response functions. In the baseline specification, restrictions are binding for twelve months following the shock ${ }^{12}$. A summary of the restrictions considered in the benchmark case is provided in Table 1.

Table 1: Identifying sign restrictions

\begin{tabular}{l|r}
\hline \hline Variable & Response to QE-shock \\
\hline CPI & $\geq 0, \quad k=0, \ldots, 11$ \\
Stock prices & \\
Ind. production & $\geq 0, \quad k=0, \ldots, 11$ \\
Reserves & $\geq 0, \quad k=0, \ldots, 11$ \\
Exchange rate & $-\epsilon \leq, \leq \epsilon, \quad k=0, \ldots, 11$ \\
Call rate & \\
Longterm yield & \\
\hline \hline
\end{tabular}

In particular, the unconventional monetary shock is identified by restricting reserves not to decrease following the shock. Since we estimate the model for a zero-lower bound situation, the call rate cannot fall further following the shock. This is implemented by means of a "near-zero" restriction; in particular, we specify the response of the call rate to stay "reasonably close" to zero following the unconventional monetary shock. Thus, $-\epsilon \leq r_{k}^{i, Q E} \leq \epsilon$, where $r_{k}^{i, Q E}$ denotes the impulse response of the call rate following a quantitative easing shock. For the baseline case we set $\epsilon=0.005 .^{13}$

Furthermore, we specify stock prices not to decrease following the QE-shock. Admittedly, we already take a stance on the importance of stock prices in the transmission of monetary policy when postulating this restriction, assuming an increased demand in and thus a rising price of these financial assets. This assumption is in line with Meltzer $(1995,2001)$ and Mishkin (2001) suggesting the existence of portfolio rebalancing effects after a monetary policy shock. In particular, the monetarist asset market equilibrium framework in Meltzer (1995) points to increased purchases of real capital and financial assets on the side of investors after a base money injection by the central bank driving up asset prices. In theory, this result also holds in a liquidity

\footnotetext{
${ }^{12}$ for instance, Scholl and Uhlig (2005) use a similar restriction horizon.

${ }^{13}$ While varying $\epsilon$ does not change our main results, lower values of the parameter of course lead to a more restrictive specification and thus to an increased computational effort.
} 
trap situation. While, following an increase in the monetary base, the interest rate does not move, increased asset purchases still take place due to the excess money supply in the economy leading to a rise in respective prices. ${ }^{14}$ The particular importance of stock prices in the transmission process of monetary policy in Japan has been documented in previous studies. For instance, Oda and Okina (2001) describe this transmission channel for Japan. In the case of outright purchases of long-term government bonds as part of the QE-program conducted by the Bank of Japan, a certain share of the portfolios of banks and other institutional investors is converted into base money. The consequent reduction in portfolio risk offers new risk-taking possibilities in an attempt of utility maximizing investors to retain equilibrium. This may lead to an increased purchase of risky assets such as corporate bonds and equities. Of course, the magnitude of this effect is conditional on, first, the quantity of long-term bonds purchased by the Bank of Japan, and second, the extent to which investors are willing to engage in increased risk-taking. This latter point is especially relevant in the case of Japan, where banks and institutional investors have traditionally abstained from excessive risk-taking. Thus, the question concerning the effects of portfolio rebalancing is ultimately, of course, an empirical one. For instance, Miyao (2002) offers an econometric investigation of this issue. He includes stock prices in a VAR framework for Japan and finds a positive reaction of this variable to an expansionary monetary base shock for the pre-1995 period. Furthermore, Kamada and Sugo (2006) find that including stock prices in a VAR model leads to a faster increase in output following an expansionary monetary shock for different post-1995 sample periods.

Moreover, we restrict the effective exchange rate not to decrease following a QE-shock, implying a real depreciation of the Yen. For the exchange rate, the reasoning is similar as for asset prices; because of portfolio rebalancing effects, the exchange rate is likely to rise after an expansionary shock even if the interest rate does not react. For instance, Kamada and Sugo (2006) use a similar restriction on the exchange rate. Because the central question assessed in this paper is concerned with the effectiveness of unconventional monetary policy measures on economic activity and prices at the zero-lower bound, which is the ultimate concern of central banks facing a liquidity trap situation, we leave the consumer price index as well as industrial production unrestricted. Moreover, we abstain from restricting the 10-year government yield. As discussed in the last section, the effects of quantitative easing on longterm yields is theoretically not clear; observing rising yields following a base money expansion may be possible as a consequence of

\footnotetext{
${ }^{14}$ The potentially important role of asset prices in the transmission of expansionary monetary policy in a zero-lower bound situation has also been noted by Bernanke (1999).
} 
increasing inflation expectations. In this sense our identification scheme can be considered "agnostic" in that we let the data speak concerning the effects of an unconventional monetary shock on the real economy and longterm interest rates.

Numerically, following e.g. Canova and Nicolo (2002) or Uhlig (2005), the sign restriction approach is implemented by taking draws for the VAR parameters from the Normal-Whishart posterior ${ }^{15}$, constructing an impulse vector for each draw and calculating the corresponding impulse responses for all variables over the specified horizon ${ }^{16}$. If all these responses meet the sign restrictions, the draw is kept, otherwise it is discarded. The impulse response functions for the respective variables are then calculated as the median of all "successful" draws. For the analysis at hand, the procedure is repeated until 1000 draws are found satisfying the restrictions. In contrast to identification strategies based on Cholesky or Blanchard-Quah decompositions, the sign restriction approach explicitly incorporates assumptions that are often used implicitly allowing a more transparent procedure. Moreover, imposing zero restrictions on contemporaneous or long-run impulse responses is avoided. While zero-restrictions on contemporaneous interactions may not hold in reality (Faust, 1998), long-run restrictions may be biased in small samples (Faust and Leeper, 1997). For comparison, however, we additionally estimate the model using an identification strategy based on a Cholesky decomposition. Results are reported in Section 6.3.

\subsection{Identifying three shocks}

In order to exclude the possibility that other disturbances enter the identified unconventional monetary shock, we extend the above-explained identification setup. In particular, next to the QE-shock we additionally identify two traditional shocks; a positive demand and a positive supply shock. To be able to distinguish between the responses to the respective shocks, we require these disturbances to be orthogonal to the monetary shock. ${ }^{17}$ Using this specification we make sure that the expansionary monetary shock is not confused with disturbances that relate to business cycle fluctuations. In identifying the additional shocks we explicitly stick with

\footnotetext{
${ }^{15}$ Uhlig (1994) offers a detailed discussion on the Normal-Wishart prior. His proposition 5 states that in the case of nonexplosive roots, i.e. $|\rho| \leq 1$, using a flat Normal-Wishart prior is equivalent to using a critics prior in practical applications. While the Normal-Wishart prior puts equal weights on all values of $\rho$, the critics prior emphasizes larger values of $\rho$ and is thus consistent with the prior belief that unit roots are likely.

${ }^{16}$ Estimation was performed by using Fabio Canova's Matlab codes bvar.m, bvar_chol_impulse.m and bvar_sign_ident.m which can be downloaded from his website http://www.crei.cat/people/canova/.

${ }^{17}$ Mountford and Uhlig (2009) show how the identification setup in Uhlig (2005) can be extended to control for additional shocks. Our estimation strategy closely follows their approach.
} 
our ZLB assumption and base the restrictions on a simple AS-AD scheme adapted to a liquidity trap situation. The restrictions for the extended identification scheme are summarised in Table 2:

Table 2: Identifying sign restrictions - three shocks

\begin{tabular}{l|c|c|c|c}
\hline \hline & \multicolumn{3}{|c|}{ Response to } & Restriction horizon \\
Variable & Demand shock & Supply shock & QE shock & \\
\hline CPI & $\geq 0$ & $\leq 0$ & & $k=0, \ldots, 11$ \\
Stock prices & & & $\geq 0$ & $k=0, \ldots, 11$ \\
Ind. production & $\geq 0$ & $-\epsilon \leq, \leq \epsilon$ & & $k=0, \ldots, 11$ \\
Reserves & & & $\geq 0$ & $k=0, \ldots, 11$ \\
Exchange rate & $\leq 0$ & & $\geq 0$ & $k=0, \ldots, 11$ \\
Call rate & $\geq 0$ & $-\epsilon \leq, \leq \epsilon$ & $-\epsilon \leq, \leq \epsilon$ & $k=0, \ldots, 11$ \\
Longterm yield & & & & \\
\hline \hline
\end{tabular}

A positive aggregate demand shock leads to a non-negative response in consumer prices and industrial production. Moreover, the nominal interest rate positively responds to the shock. This is a rather traditional set of restrictions that has been used by, for instance, Canova et al. (2007) and is valid both under "normal" circumstances as well as at the ZLB. Additionally, we restrict the exchange rate to appreciate after a positive demand shock, which is reasonable in the case of a domestic demand disturbance. In the case of a positive supply shock, the identification is somewhat complicated by the ZLB constraint and thus differs from a traditional specification. In particular, industrial production is fixed in the liquidity trap case, which is reflected by the "near-zero" restriction shown in Table 2. Furthermore, the call rate is constrained not to fall below zero resulting in a similar restriction for this variable. The consumer price index is specified not to increase following a positive supply shock.

The rationale for the restriction setup for the traditional shocks under liquidity trap conditions can be seen more clearly in the simple AS-AD framework shown in Figure 5. At the ZLB, characterized by the usual horizontal LM curve, the AD-curve is vertical. Thus, a positive supply shock that shifts the AS-curve to the right only results in a lower price level without changing output. In Figure 5, a shift of the AS-curve leads to a new price level $P_{1}$ with $P_{0}<P_{1}$, while output remains unchanged at $Y_{0}$. Moreover, in the IS-LM diagram, an increased price due to the shock does not result in a shift of the LM-curve under liquidity trap conditions. Thus, the interest rate is fixed at $i_{0}$, resulting in a corresponding "near-zero" restriction on the call rate as 
shown in Table 2.

Figure 5: Supply shock at the zero-lower bound
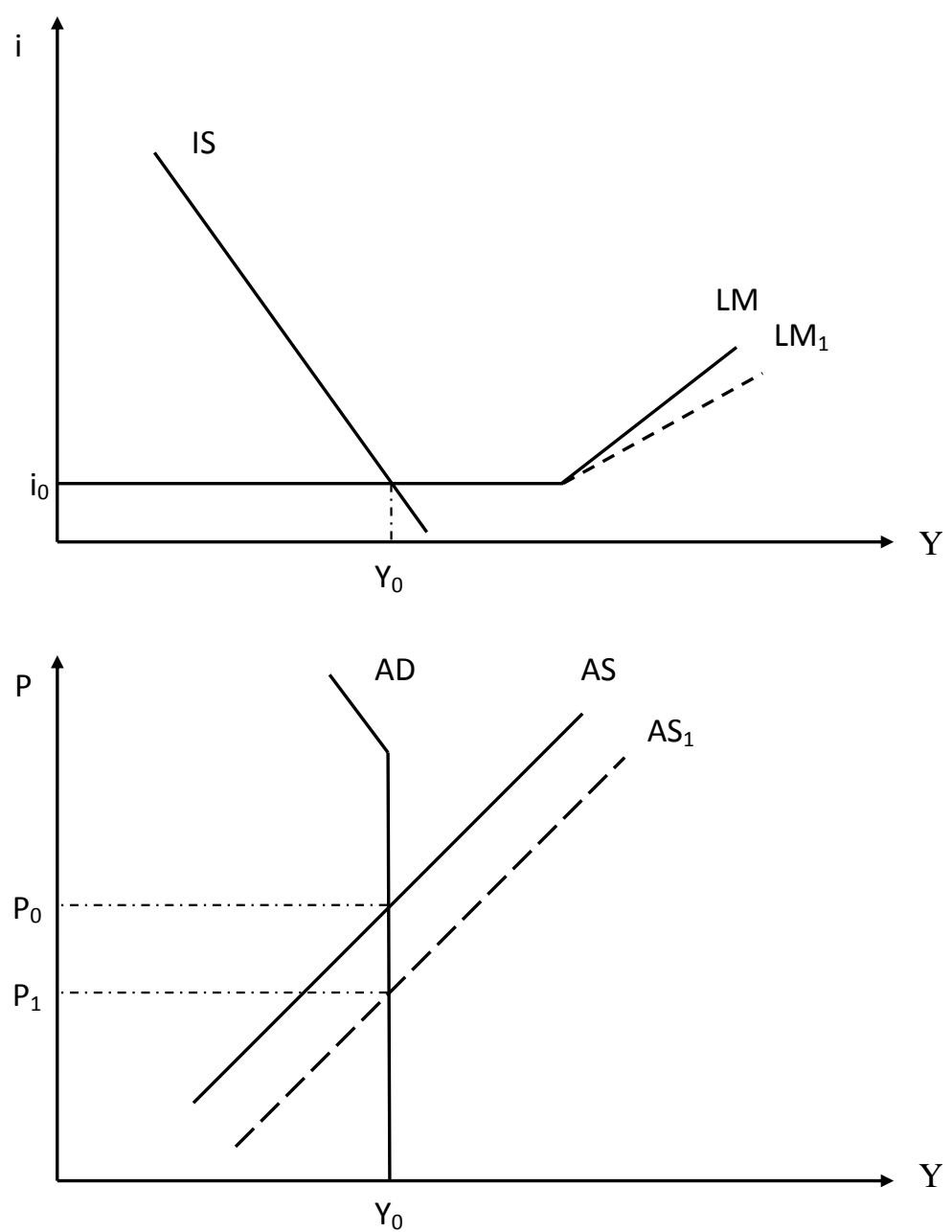


\section{Data}

In the benchmark case we include six variables reflecting the macroeconomic and monetary environment of the Japanese economy. We use monthly observations for the period of January 1995 to September 2010. The start of the sample period is mainly motivated by the fact that the Bank of Japan first decreased nominal interest rates to below 1\% during the course of 1995 and we are mainly interested in the effectiveness of monetary policy at near-zero interest rates. As far as the monetary variables are concerned, we include the call rate as well as the monetary base. These two series have been obtained from the Bank of Japan's statistics website. The uncollateralized overnight call rate, which we include as monthly average, is generally seen as the target rate for the Japanese Central Bank from July 1985 (Miyao, 2002). To be able to identify the QE-shock we include the average outstanding current account balances held by financial institutions at the Bank of Japan. This is the part of the monetary base that can be referred to as reserves held at the central bank. Under the ZLB constraint this variable has gained importance as the main operating target for the Bank of Japan.

Moreover, we include a measure of the Japanese industrial production as a generally used indicator of economic activity as well as the consumer price index. Both indices have 2005 as base year. The stock price series is the Nikkei 225 stock price index. While the measures of industrial production and the consumer price index are obtained from datastream, data on the Nikkei index can be found at the statistics website of the Bank of Japan. The measure of industrial production and the consumer price index, stock prices, the exchange rate as well as both monetary measures are seasonally adjusted by X12-ARIMA.

\section{Results}

\subsection{Benchmark case}

In the benchmark case we only identify the QE-shock, which of course is our main focus of interest in this analysis. Figure 6 shows the impulse responses to this shock based on the restriction setup explained above. In the figure, the solid lines denote the median impulse responses from a Bayesian vector autoregression with 1000 draws, while the dashed lines indicate one-standard error confidence bands. The responses of stock prices and the current account component of the monetary base have been restricted not to decrease following the shock, so the immediate 
responses are not surprising by construction. As preset, stock prices increase on impact and stay above the zero line for more than two years - considerably longer than restricted. Moreover, the response is rather strong amounting to almost $2 \%$ in the first months following the shock. This suggests that stock prices clearly respond to a monetary base shock pointing to the validity of restricting this variable. Reserves rise and stay above the zero line slightly longer than preset. Surprisingly, the response suggests a monetary tightening after about two years following the expansionary shock. Uhlig (2005) and Kamada and Sugo (2006) find similar results in their analyses of the real effects of monetary policy for the U.S. and Japan, respectively. In these studies, this phenomenon is mainly justified by suggesting that the monetary shock might be due to an incorrect assessment of economic conditions by the central bank and is followed by a policy reversal. As restricted, the call rate stays close to zero following the shock. After a year, however, it increases slightly and rises to about $0.01 \%$ approximately three years after the shock.

Figure 6: Impulse responses to a QE-shock
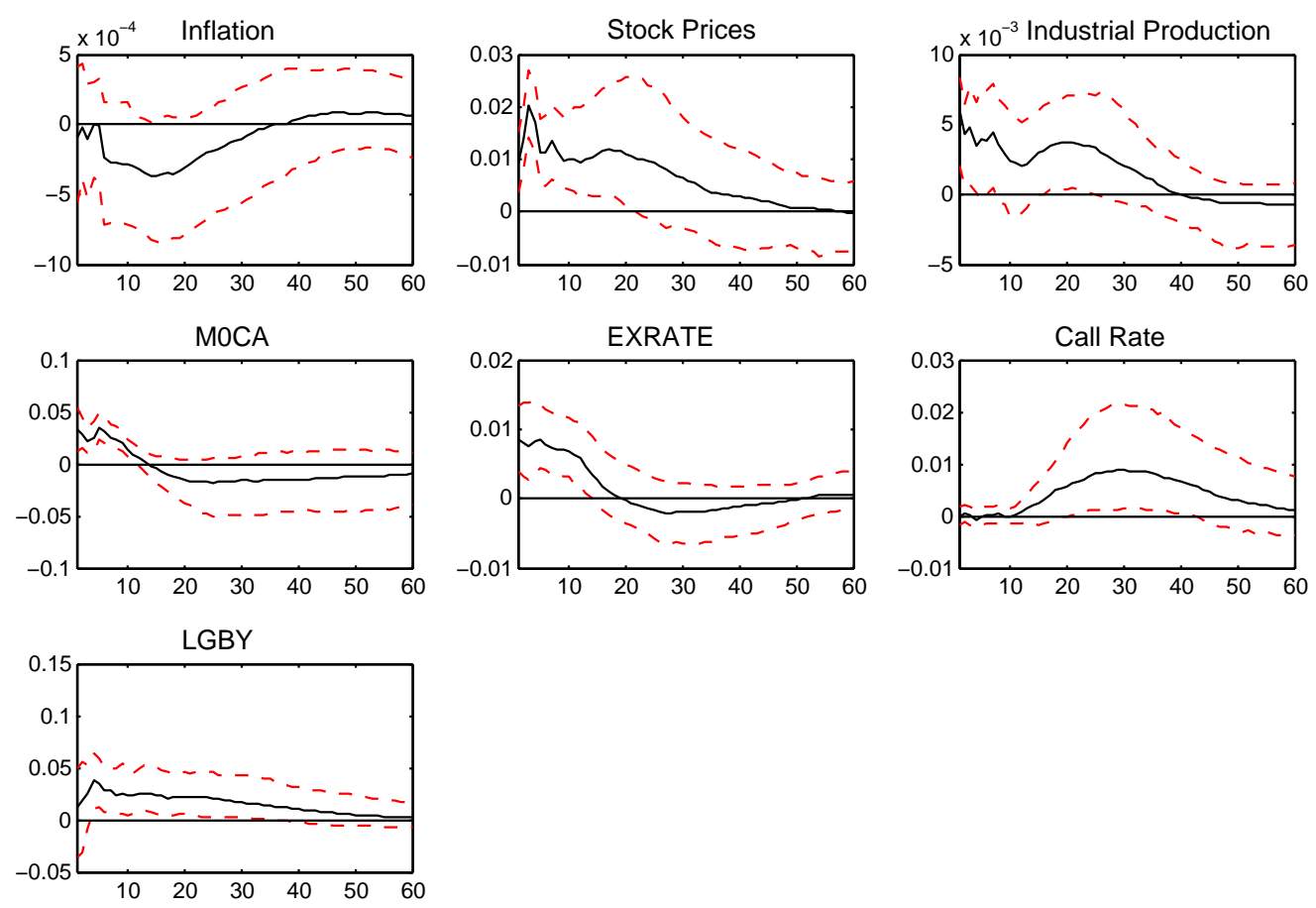

As restricted, the exchange rate raises following the shock indicating a real depreciation of the Yen, which lasts somewhat longer than preset. Importantly, as explained above, the variables of interest have been left unrestricted. Figure 6 shows that an expansionary shock leads to a 
significant increase of industrial production by about $0.5 \%$ on impact. The effect of the shock lasts for about two and a half years; after this period the response becomes insignificant. By contrast, the consumer price index does not increase significantly in reaction to the QE-shock. There is a slight insignificant increase in this variable only after about a year following the shock. All in all, the results presented in Figure 6 suggest that the quantitative easing strategy adopted by the Bank of Japan in the late 90's in a situation of near-zero interest rates has been somewhat successful in stimulating economic activity, at least in the short run. However, the Bank of Japan's second main goal motivating this policy, namely to raise inflation and eventually to bring an end to Japan's deflationary episode, does not seem to have been achieved by the QE-shock.

\subsection{Identifying three shocks}

In order to prevent a confusion of the unconventional monetary shock with other disturbances related to business cycle fluctuations, our second identification scheme explained in the last section explicitly specifies two traditional shocks next to the monetary shock. These shocks have been identified in line with liquidity trap theory in order to account for the zero-lower bound situation prevailing in Japan over our sample period. Figure 7 shows the impulse responses to the first shock resulting from this identification scheme, the QE-shock. As can be seen in the figure, the qualitative results do not change after controlling for business cycle disturbances. ${ }^{18}$ Industrial production still rises to up to $0.5 \%$; however, error bands are somewhat wider. As in the benchmark case, the response of the consumer price index is not significant. The responses of the other variables are very similar to those in the benchmark case. Thus, our extended identification scheme does not change our main conclusion that while production could be increased by quantitative easing measures, inflation has not been affected by this policy.

The second shock we identify is a positive demand shock. Since this shock is mainly identified for the purpose of controlling for demand disturbances and the reactions to it are not of particular interest, most variables have been restricted. In particular, we specify the CPI and industrial production not to decrease for one year following the shock. Moreover, call rate increase after a positive demand disturbance, as suggested by simple economic theory. Impulse responses to this shock are shown in Figure 8. Interestingly, the reaction of stock prices becomes insignificant after about two months suggesting that the strong reaction of this variable reported for the benchmark

\footnotetext{
${ }^{18} \mathrm{As}$ in the last subsection, the solid lines denote the median impulse responses from a Bayesian vector autoregression with 1000 draws, while the dashed lines indicate one-standard error confidence bands.
} 
case in the last subsection is unlikely to be in fact due to demand fluctuations entering the single monetary shock.

Similarly, the variables of interest have been restricted to identify the third shock, which is a positive supply disturbance. As specified, the CPI decreases following the shock; the response function remains below the zero line for about one and a half years. Industrial production and the call rate are restricted to remain close to their steady state values after the shock. In fact, Figure 9 shows that the impulse responses for these two variables stay close to zero and are insignificant for much longer than restricted. This points to the validity of our identification scheme based on liquidity trap theory. As in the case of the demand shock stock prices do not show a significant response to the supply shock suggesting that the relatively strong reaction of this variable in the benchmark case is likely to be a reaction to a "pure" QE-shock only.

Figure 7: Three shocks - responses to a QE-shock
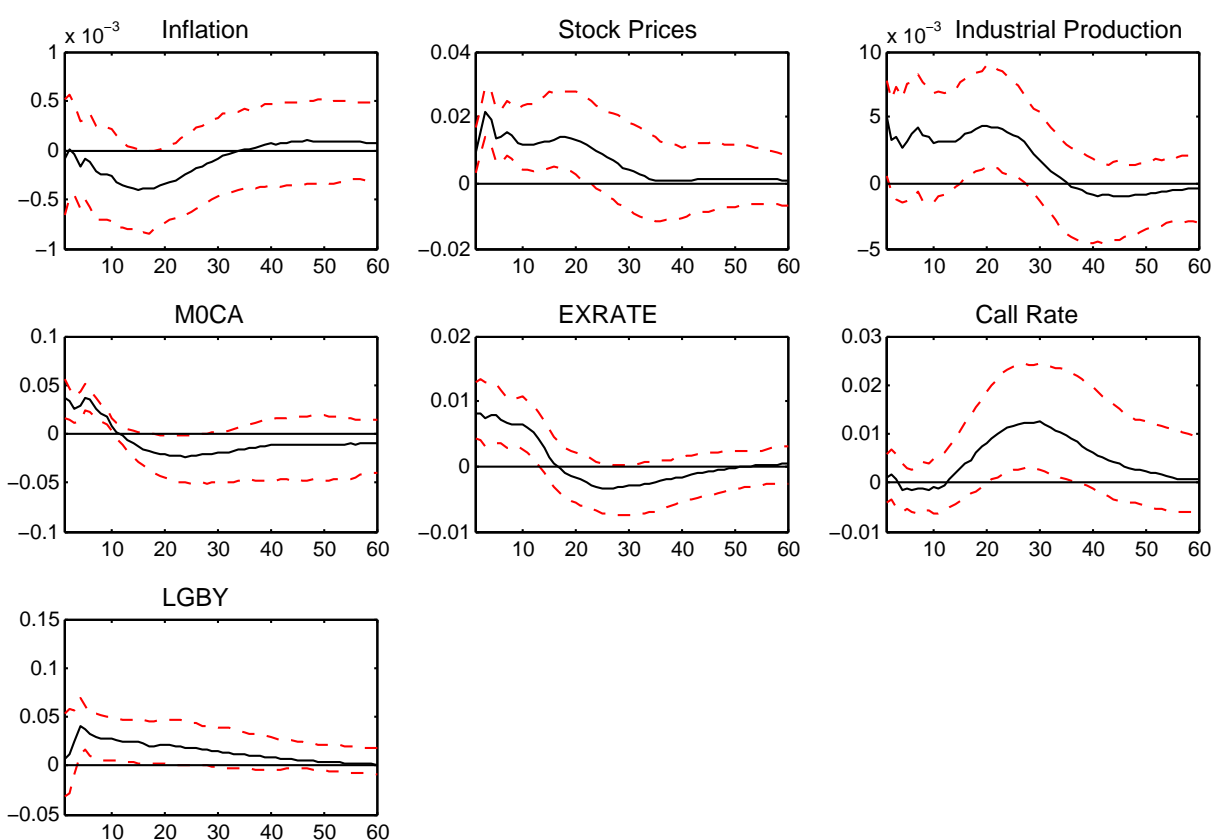
Figure 8: Three shocks - responses to a demand shock
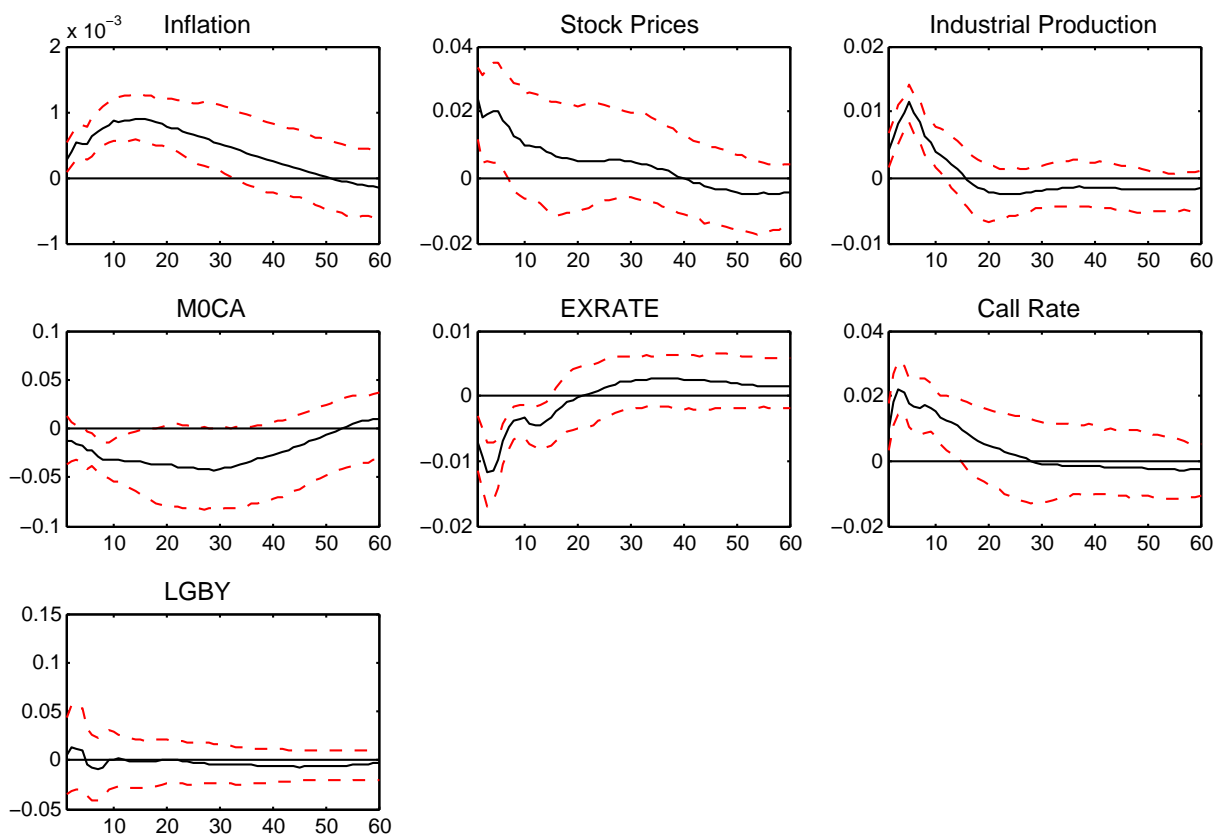

Figure 9: Three shocks - responses to a supply shock
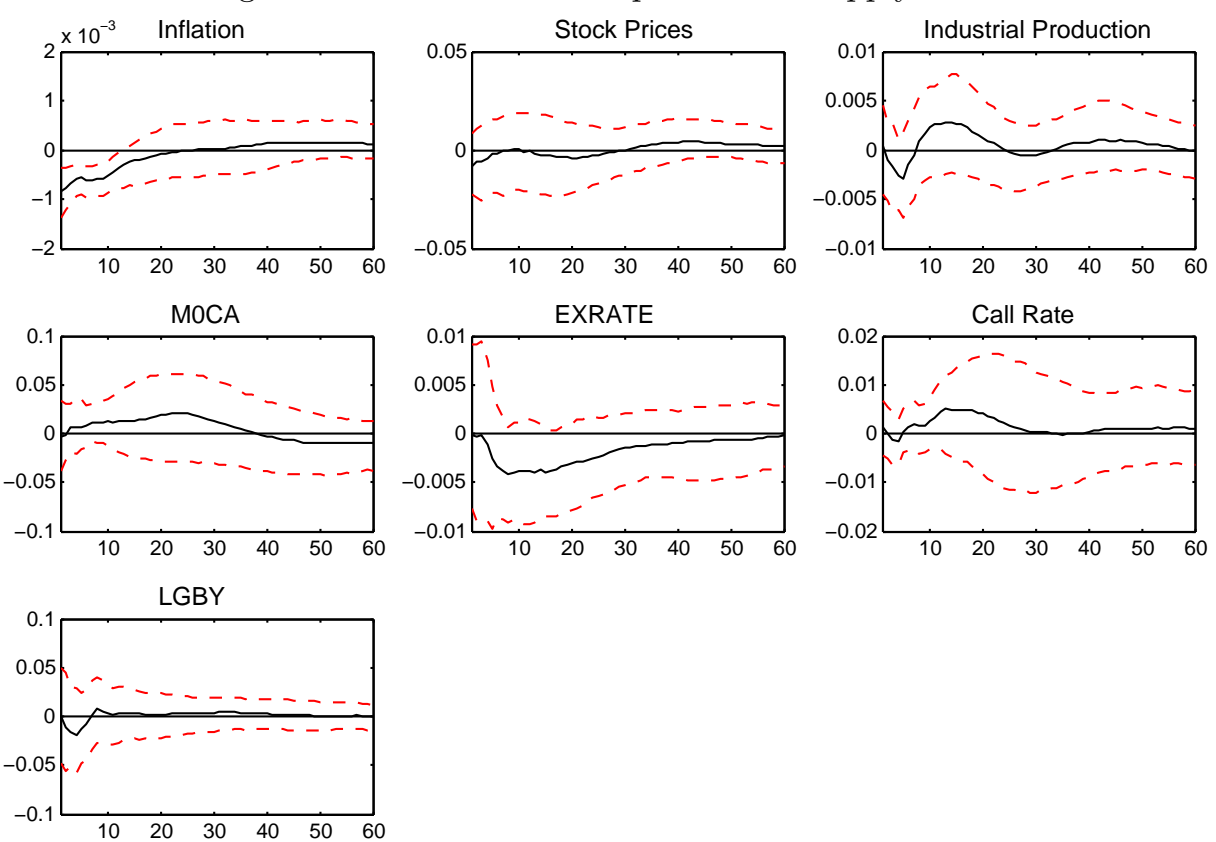


\subsection{Robustness}

Our first robustness check concerns the estimation of an alternative specification, in which we assess whether the results from the benchmark identification scheme change if we exclude the call rate from the regression. Arguably, since the call rate was ineffective as a policy instrument from the late 1990's, an inclusion of this variable is not central in the analysis of the real effects of unconventional policy.

As further robustness checks, we consider variations in the identification setup. First, we vary the set of restrictions by restricting the consumer price index instead of stock prices to increase following the unconventional shock. As a second robustness check we leave both the CPI and stock prices unrestricted. Table 3 summarises these respective alternative identification schemes ${ }^{19}$.

Table 3: Alternative sign restrictions

\begin{tabular}{l|r|r}
\hline \hline Variable & $\begin{array}{r}\text { Response to QE-shock } \\
\text { unconditional on } S P\end{array}$ & $\begin{array}{c}\text { Response to QE-shock } \\
\text { conditional on } C P I\end{array}$ \\
\hline CPI & $\geq 0, \quad k=0, \ldots, 11$ \\
$\begin{array}{l}\text { Stock prices } \\
\text { Ind. production }\end{array}$ & \\
Reserves & $\geq 0, \quad k=0, \ldots, 11$ & $\geq 0, \quad k=0, \ldots, 11$ \\
Exchange rate & $\geq 0, \quad k=0, \ldots, 11$ & $\geq 0, \quad k=0, \ldots, 11$ \\
Call rate & $-\epsilon \leq, \quad k, \quad k=0, \ldots, 11$ & $-\epsilon \leq, \leq \epsilon, \quad k=0, \ldots, 11$ \\
Longterm yield & & \\
\hline \hline
\end{tabular}

Figure 10 in the Appendix shows the impulse responses resulting from the specification that excludes the call rates. The figure shows that our results are robust to this variation indicating that indeed the call rate did not fluctuate a lot during the period we consider and that it's role as a policy instrument is negligible over this period. The following three figures show the results based on our alternative identification schemes. Figure 11 shows impulse responses to a QE-shock conditional on a rise in the CPI. As preset the CPI rises on impact; however, the response becomes insignificant soon after the end of the restriction horizon of twelve months. While the response of stock prices has the expected sign, it is insignificant. The remaining response functions are,

\footnotetext{
${ }^{19}$ Furthermore, we check robustness of our results to a change of the sample period from 1990-2010, to including the core CPI instead of the all-items CPI, to include the US/YEN exchange rate instead ot the real effective exchange rate as well as to variations in the lag length. Our main results are robust to all of these variations. Detailed regression results are available upon request.
} 
however, qualitatively similar to the benchmark case. In particular, industrial production rises on impact to above $0.5 \%$; however, the effect does not last as long as in the benchmark case. Figure 12 shows the results based on the identification scheme without the restriction on stock prices. From this figure it is clear, that the response of output is not robust to this specification. Moreover, the CPI even decreases significantly for several months. However, this could also be a sign of a degrees of freedom problem in our estimation. Including seven variables and six lags as well as a constant and a time trend results in a large number of parameters to estimate for relative to the llimited number of variables. Thus, Figure 13 shows an alternative specification which only includes the CPI, industrial production, reserves, the exchange rate as well as the call rate. The stock price index as well as the longterm government yield are excluded from this specification in order to archieve parsimony with respect to the parameters to estimate. Moreover, we only include four lags in this specification. The results displayed in Figure 13 clearly show that with this reduced specification, the response of output is significantly positive. Thus, with respect to economic activity, our main results still hold if we exclude the stock price and make sure to have a sufficient number of free parameters.

Our final robustness check is concerned with the restriction horizon. As noted by, for instance, Uhlig (2005), it is difficult to base the choice of the appropriate restriction horizon on economic theory resulting in some degree of arbitrariness in specifying this parameter. We therefore estimate the benchmark model for different restriction horizons to assess to what extent our results are sensitive to such changes. Figure 14 in the Appendix shows the impulse response functions for our variables of interest, CPI and industrial production, for restriction horizons $k=6, k=12$ and $k=18$. It can be seen in the figure that our main results are qualitatively insensitive to variations in $\mathrm{k}$; while prices do not show any significant reaction in all of these cases, industrial production increases significantly. However, the magnitude of this increase differs among the respective cases. While for $k=6$, the positive impact on economic activity is significant only with a delay and vanishes rather fast following the shock, the response is stronger and lasts somewhat longer for $k=18$ as compared to the benchmark case, $k=12$. Moreover, results for $k=9, k=15$ and $k=21$ that are not reported here ${ }^{20}$ are similar in that the response of industrial production is more pronounced and also more persistent for larger restriction horizons.

\footnotetext{
${ }^{20}$ These results are available upon request.
} 


\section{Discussion and Conclusion}

The primary objective of this paper has been to agnostically assess the real effects of QE measures adopted by the Bank of Japan for a liquidity trap episode. Our empirical results show that unconventional monetary policy can positively affect real economic activity even when the economy is in the liquidity trap. However, the QE-shocks we identify do not significantly affect inflation. We believe these results are interesting not only for the Japanese economy, but also for other advanced economies where monetary policy is constrained by the ZLB.

Even though a detailed analysis of particular transmission channels of quantitative easing is beyond the scope of this study, our results suggest some tentative statements concerning the transmission of unconventional policy in Japan. Bernanke and Reinhart (2004) define three channels through which a base money expansion may potentially affect the economy. The first channel involves portfolio rebalancing effects a la Meltzer (1995) that have been discussed above. If money and other assets in the economy are imperfect substitutes, a base money injection induces investors to shift part of the additionally liquidity into other asset investments reducing the corresponding yields. Lower yields on these (longterm) assets may in turn stimulate private investment and thus economic activity. Second, QE measure may change expectations concerning future shortterm interest rates. A commitment to a permanent high level of reserves may even be more credible and thus more effective than an announcement of permanently low interest rates because it is more visible. Theoretically, via the expectations hypothesis, lower future shortterm rates may lead to decreasing current longterm rates, which again may have stimulating effects. Finally, a base money expansion can also have expansionary fiscal effects, again under the assumption that the public expects the measures to be relatively long-lasting. Since the central bank replaces publicly held interest-bearing government debt with currency on its balance sheet, the public may expect a lower effective tax burden. This channel is analyzed in Auerbach and Obstfeld (2005) by means of a DSGE model for Japan. A further channel, mentioned for instance by Oda and Okina (2001) also refers to portfolio balancing effects but postulated rather direct effect. Liquidity injections by the central bank lead to a reduction in portfolio risk, which offers new risk-taking possibilities in an attempt of utility maximizing investors to retain equilibrium. This may, in turn, lead to an increased purchase of risky assets such as corporate bonds and equities. 
Our empirical analysis shows that the longterm government bond yield does not fall, in fact it rises slightly. Therefore, our results suggest only minor importance of the classical portfolio rebalancing channel as well as the expectations channel in Japan. Instead our results imply a more direct portfolio shift by investors towards riskier assets such as, most notably, equities. 


\section{A Appendix}

Figure 10: Impulse responses to a QE-shock - excluding the call rate
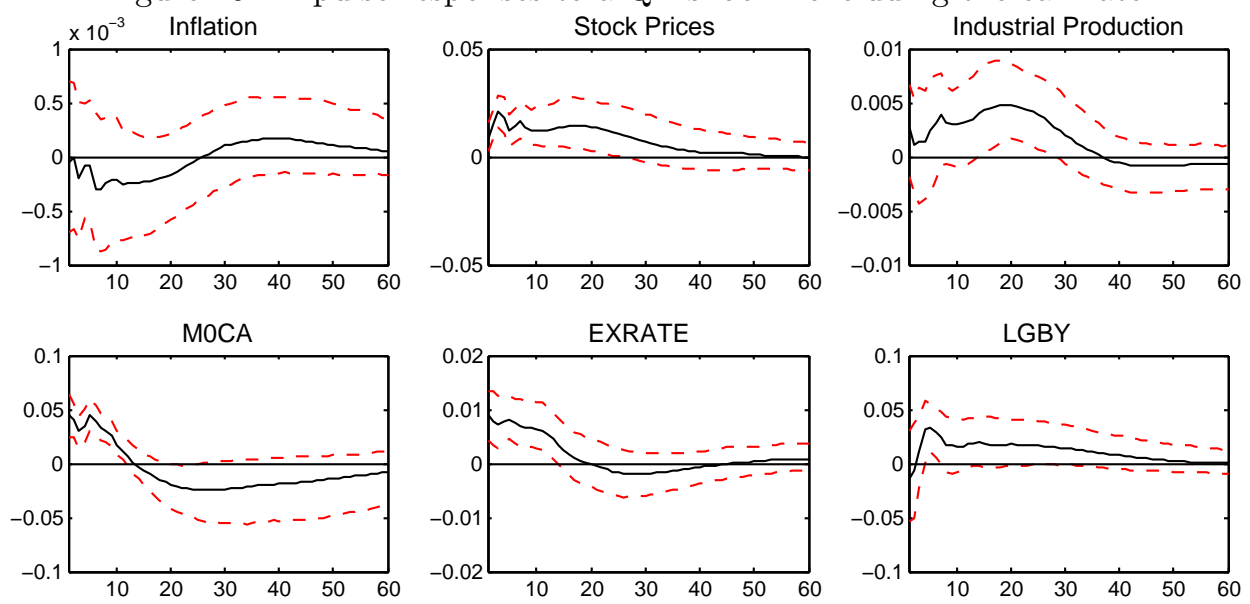

Figure 11: Impulse responses to a QE-shock - restricting inflation
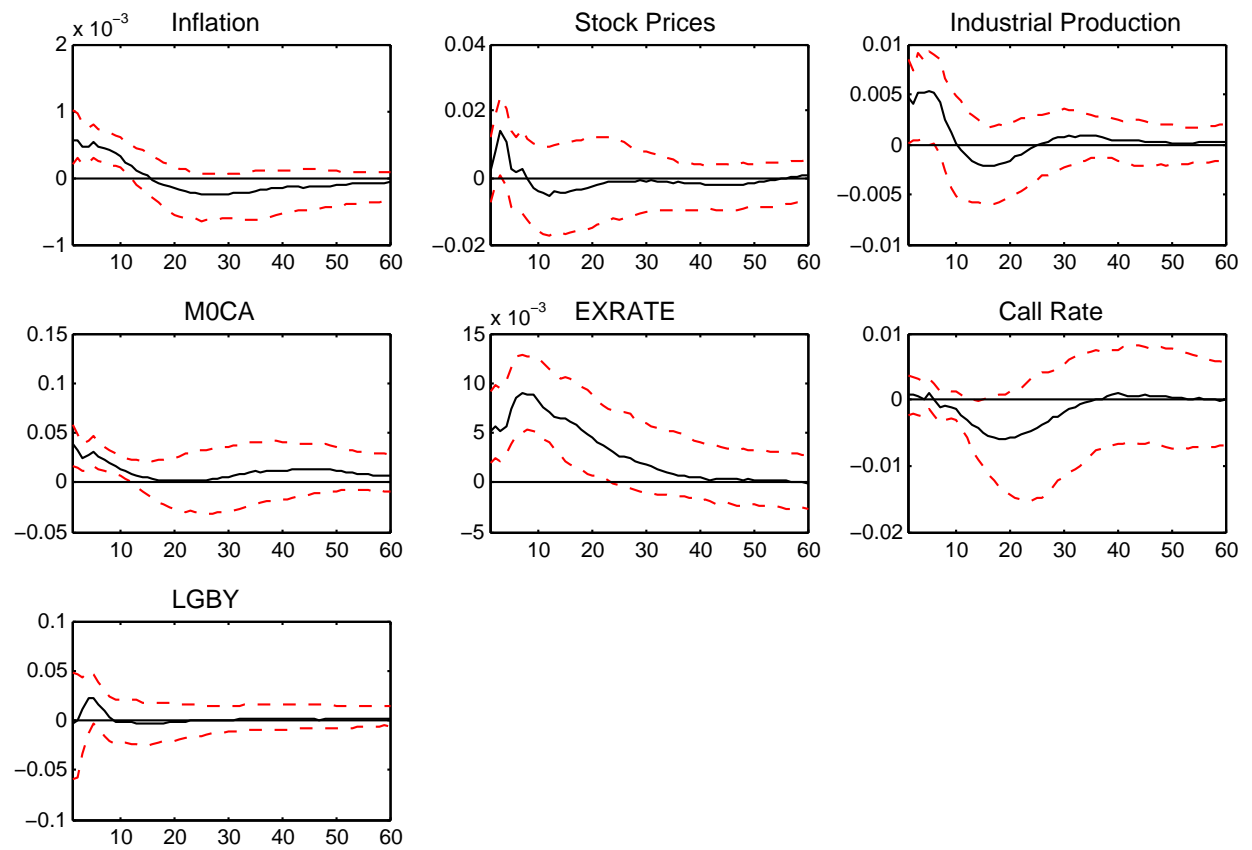
Figure 12: Impulse responses to a QE-shock - unconditional on stock price
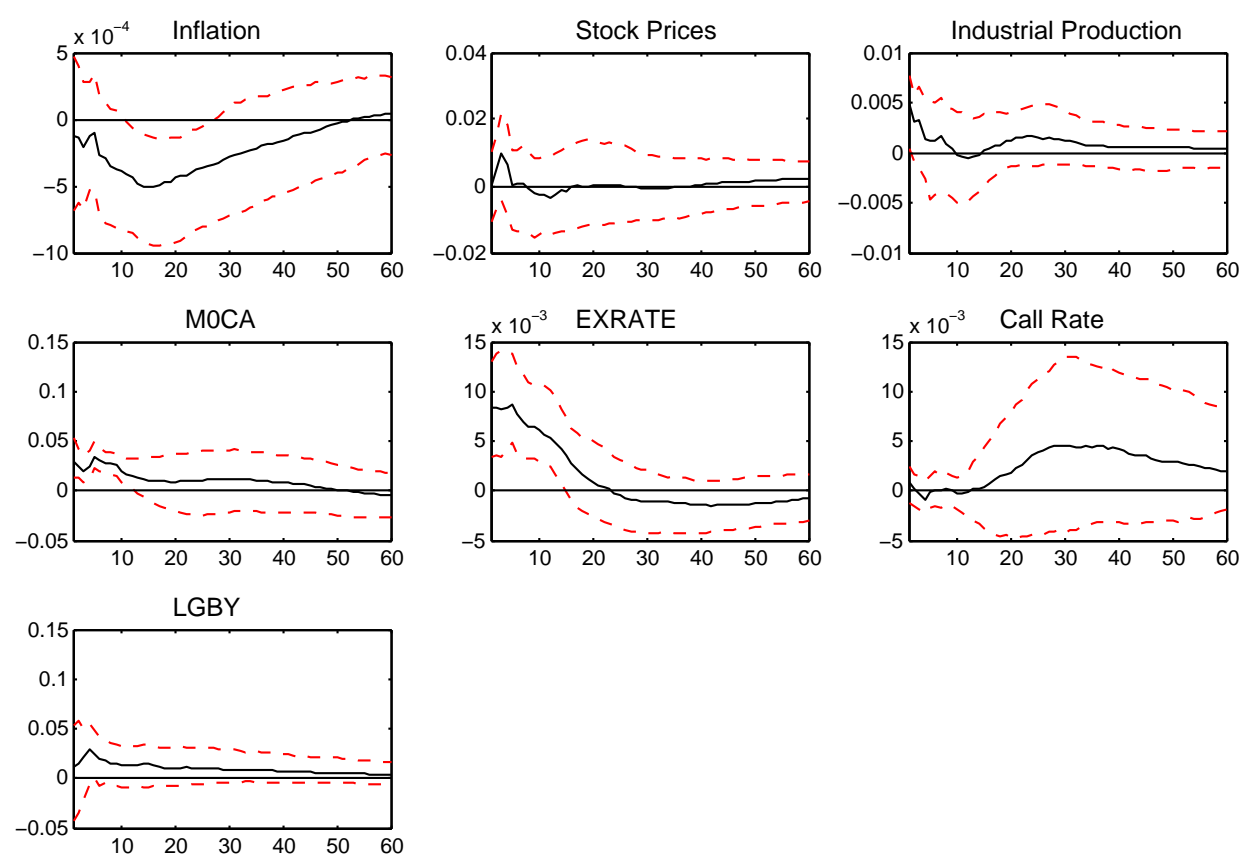

Figure 13: Impulse responses to a QE-shock - excluding the stock price
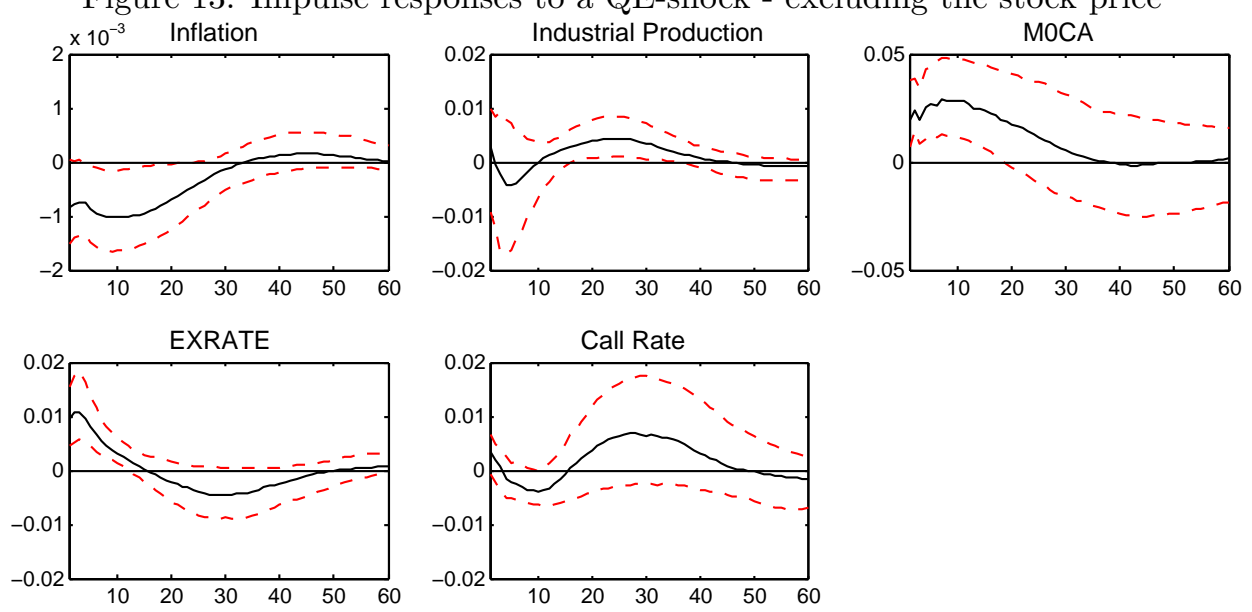
Figure 14: Impulse responses to a QE-shock - varying the restriction horizon
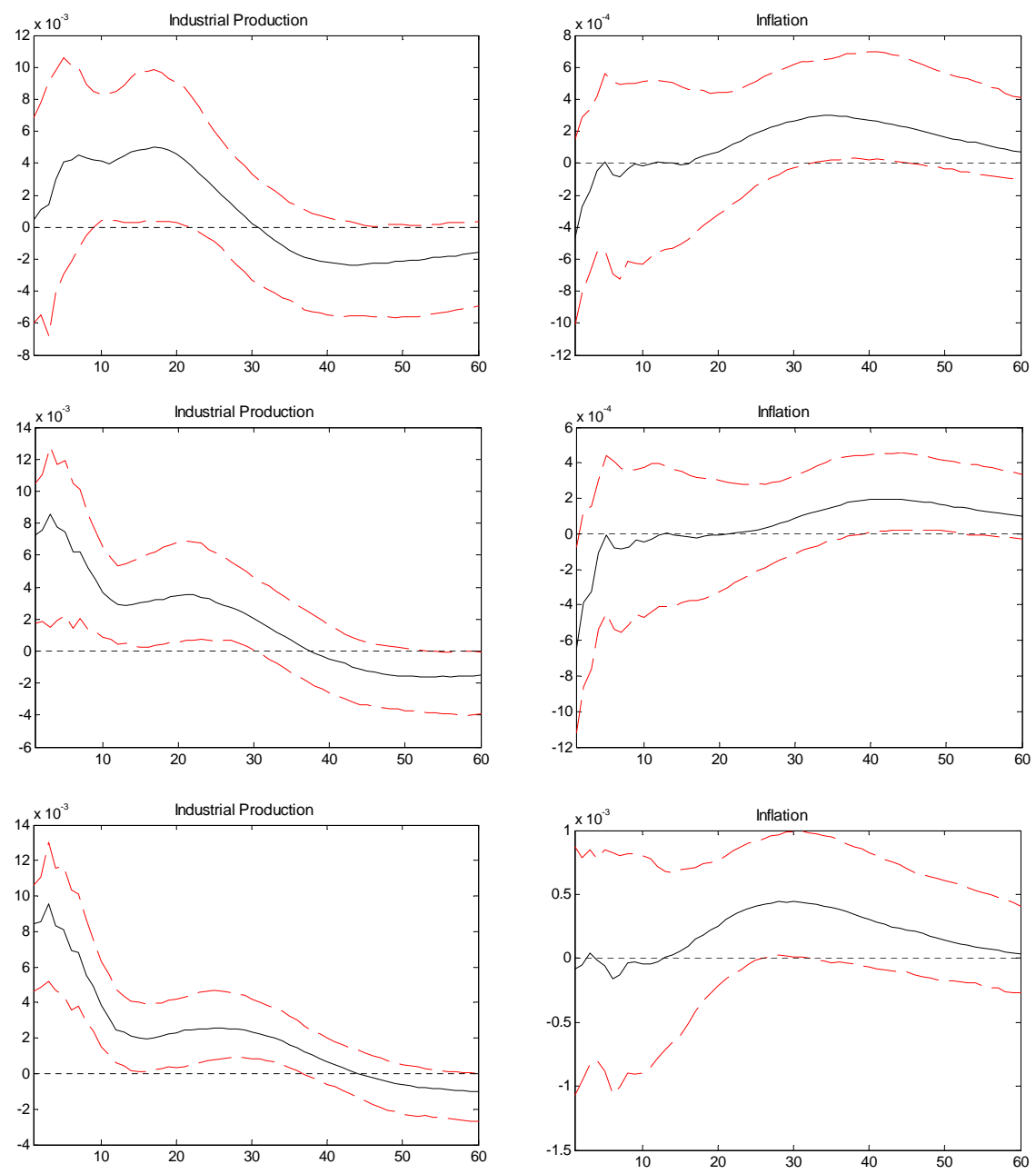


\section{References}

Auerbach, A. J., and Obstfeld, M. (2005). "The case for open-market purchases in a liquidity trap." American Economic Review, 95(1), 110-137.

Baumeister, C., and Benati, L. (2010). "Unconventional monetary policy and the great recession - estimating the impact of a compression in the yield spread at the zero lower bound." Working Paper Series 1258, European Central Bank.

Bernanke, B. S. (1999). "Japanese monetary policy: A case of selfinduced paralysis." In Institute for International Economics Special Report 13: Japans Financial Crisis and Its Parallels.

Bernanke, B. S. (2002). "Deflation: making sure it doesn't happen here : remarks before the national economists club, washington, d.c., november 21, 2002." Speech.

Bernanke, B. S., and Reinhart, V. R. (2004). "Conducting monetary policy at very low short-term interest rates." American Economic Review, 94(2), 85-90.

Bernanke, B. S., Reinhart, V. R., and Sack, B. P. (2004). "Monetary policy alternatives at the zero bound: An empirical assessment." Brookings Papers on Economic Activity, 35(2004-2), $1-100$.

Canova, F., Gambetti, L., and Pappa, E. (2007). "The structural dynamics of output growth and inflation: Some international evidence." Economic Journal, 117(519), C167-C191.

Canova, F., and Nicolo, G. D. (2002). "Monetary disturbances matter for business fluctuations in the g-7." Journal of Monetary Economics, 49(6), 1131-1159.

Christiano, L. J., Eichenbaum, M., and Evans, C. L. (1998). "Monetary policy shocks: What have we learned and to what end?" NBER Working Papers 6400, National Bureau of Economic Research, Inc.

Doh, T. (2010). "The efficacy of large-scale asset purchases at the zero lower bound." Economic Review, (Q II), 5-34.

ECB (2010). "Ecb monthly bulletin - october." Monthly bulletin, European Central Bank.

Faust, J. (1998). "The robustness of identified var conclusions about money." International Finance Discussion Papers 610, Board of Governors of the Federal Reserve System (U.S.). 
Faust, J., and Leeper, E. M. (1997). "When do long-run identifying restrictions give reliable results?" Journal of Business \& Economic Statistics, 15(3), 345-53.

Gagnon, J., Raskin, M., Remache, J., and Sack, B. (2010). "Large-scale asset purchases by the federal reserve: did they work?" Staff Reports 441, Federal Reserve Bank of New York.

Hamilton, J. D., and Wu, J. (2010). "The effectiveness of alternative monetary policy tools in a zero lower bound environment." mimeo.

Illing, G., and Watzka, S. (2010). "Eine neubewertung der geldpolitischen reaktionen von ezb und fed auf die finanzkrise." Zeitschrift für das gesamte Kreditwesen.

Jinushi, Kuroki, and Miyao (2000). "Monetary policy since the late 1980s: delayed policy actions." In R. Mikitani, and A. S. Posen (Eds.), Japans' financial crisis and its parallels to US experience, Japans' financial crisis and its parallels to US experience, Institute for International Economics.

Kamada, K., and Sugo, T. (2006). "Evaluating japanese monetary policy under the nonnegativity constraint on nominal short-term interest rates." Bank of japan working paper series, Bank of Japan.

Krugman, P. R. (1998). "It's baaack: Japan's slump and the return of the liquidity trap." Brookings Papers on Economic Activity, 29(1998-2), 137-206.

Lanne, M., and Lütkepohl, H. (2008). "Identifying monetary policy shocks via changes in volatility." Journal of Money, Credit and Banking, 40(6), 1131-1149.

Lenza, M., Pill, H., and Reichlin, L. (2010). "Monetary policy in exceptional times." Economic Policy, 25, 295-339.

Meier, A. (2009). "Panacea, curse, or nonevent? unconventional monetary policy in the united kingdom." IMF Working Papers 09/163, International Monetary Fund.

Meltzer, A. H. (1995). "Monetary, credit and (other) transmission processes: A monetarist perspective." Journal of Economic Perspectives, 9(4), 49-72.

Meltzer, A.-H. (2001). "Monetary transmission at low inflation: Some clues from japan in the 1990s." Monetary and Economic Studies, 19(S1), 13-34. 
Mikitani, R., and Posen, A. S. (Eds.) (2000). Japans' financial crisis and its parallels to US experience. Institute for International Economics.

Mishkin, F. S. (2001). "The transmission mechanism and the role of asset prices in monetary policy." NBER Working Papers 8617, National Bureau of Economic Research, Inc.

Miyao, R. (2002). "The effects of monetary policy in japan." Journal of Money, Credit and Banking, 34(2), 376-92.

Miyao, R. (2005). "Use of the money supply in the conduct of japan's monetary policy: Reexamining the time-series evidence." The Japanese Economic Review, 56(2), 165-187.

Mountford, A., and Uhlig, H. (2009). "What are the effects of fiscal policy shocks?" Journal of Applied Econometrics, 24(6), 960-992.

Oda, N., and Okina, K. (2001). "Further monetary easing policies under the non-negativity constraints of nominal interest rates: Summary of the discussion based on japan's experience." Monetary and Economic Studies, $19(\mathrm{~S} 1), 323-360$.

Oda, N., and Ueda, K. (2007). "The effects of the bank of japan's zero interest rate commitment and quantitative monetary easing on the yield curve: A macro-finance approach." The Japanese Economic Review, 58(3), 303-328.

Scholl, A., and Uhlig, H. (2005). "New evidence on the puzzles. results from agnostic identification on monetary policy and exchange rates." SFB 649 Discussion Papers SFB649DP2005-037, Sonderforschungsbereich 649, Humboldt University, Berlin, Germany.

Sims, C. A. (1980). "Macroeconomics and reality." Econometrica, 48(1), 1-48.

Sims, C. A., Stock, J. H., and Watson, M. W. (1990). "Inference in linear time series models with some unit roots." Econometrica, 58(1), 113-44.

Stroebel, J. C., and Taylor, J. B. (2009). "Estimated impact of the feds mortgage-backed securities purchase program." NBER Working Papers 15626, National Bureau of Economic Research, Inc.

Svensson, L. E. O. (2003). "Escaping from a liquidity trap and deflation: The foolproof way and others." Journal of Economic Perspectives, 17(4), 145-166. 
Ueda, K. (2010). "Japan's deflation and the bank of japan's experience with non-traditional monetary policy." CIRJE F-Series CIRJE-F-775, CIRJE, Faculty of Economics, University of Tokyo.

Ugai, H. (2007). "Effects of the quantitative easing policy: A survey of empirical analyses." Monetary and Economic Studies, 25(1), 1-48.

Uhlig, H. (1994). "What macroeconomists should know about unit roots: A bayesian perspective." Econometric Theory, 10(3-4), 645-671.

Uhlig, H. (2005). "What are the effects of monetary policy on output? results from an agnostic identification procedure." Journal of Monetary Economics, 52(2), 381-419. 